\title{
A Primary Posterior Mediastinal Hydatid Cyst Manifesting as Acute Coronary Syndrome
}

Sara Belabyad*, Ganse Fongnikin Ismael Gildas, Hafssa Rouam, Dounia benzeroual, Saloua El Karimi, Mustapha El Hattaoui

Cardiology Department, Mohammed VI University Hospital, Marrakesh, CHU Mohammed VI BP2360 Principal، Avenue Ibn Sina, Marrakesh, Morocco

DOI: $10.36347 /$ sasjm.2020.v06i01.002

| Received: 05.01.2020 | Accepted: 12.01.2020 | Published: 22.01.2020

*Corresponding author: Sara Belabyad

\section{Abstract}

Hydatid disease remains a serious health problem for the Mediterranean countries, such as Morocco. Living in a rural area is an important risk factor for the disease. Hydatid cysts are usually located in the liver, lung, and brain. Mediastinal hydatid disease is very rare that have been only anecdotally in the literature. The pathogenesis is due to the accidental infestation of a human by a dog's dejections which contained the Taenia Echinococcus granulosus. We report a case of primary mediastinal hydatic cyst localization simulating an acute coronary syndrome.

Keywords: Hydatid cyst, Mediastinal, echinococcal disease.

Copyright @ 2020: This is an open-access article distributed under the terms of the Creative Commons Attribution license which permits unrestricted use, distribution, and reproduction in any medium for non-commercial use (NonCommercial, or CC-BY-NC) provided the original author and source are credited.

\section{INTRODUCTION}

Hydatid disease is primarily an illness of residents in rural areas who frequently come into contact with carnivores, sheep, and cows. Human hydatid disease caused by the larval form of Echinococcus granulosus has a worldwide distribution and is endemic in many countries at the Mediterranean region, the Middle and Far East, and South America [1, 2]. Morocco is also an endemic area to be studied for hydatid disease [1, 3-5]. Hydatid cyst (HC) has a predilection to locate in liver, lungs, and brain. Although many uncommon locations have been reported, the disease is rarely present in the mediastinum and poses diagnostic and therapeutic problems $[5,6]$.

We describe a unique case of a young man with mediastinal hydatic cyst localization.

\section{CASE REPORT}

A 48 year-old man patient was admitted to the emergency department with complaints of cough and chest pain spreading to the back and which progressed since a week of recent worsening 12 hours before admission. He had no history of hypertension, diabetes mellitus or smoking. His medical and family history revealed no typical symptoms, except living in a rural area. His physical examination was non-specific. His electrocardiogram (ECG) showed an ST depression in inferior with no conduction disorders. The laboratory examination showed that Cardiac troponins were high with negative kinetics, C-reactive protein level was 62 $\mathrm{mg} / \mathrm{L}$ (normal range: $0-5 \mathrm{mg} / \mathrm{l}$ ). The rest of basic metabolic panel, were normal. Chest radiography showed rounded and homogeneous left basithoracic opacity (Fig-1). Transthoracic echocardiography performed in the emergency department showed a large complex cystic retrocardiac mass, which initially was thought to represent a loculated pleural effusion.

A computed tomography (CT) showed, at the posterior mediastinum, a liquid formation with well limited contours and regular thin wall containing within cubicles separated by septa, in intimate contact with the descending aorta. After injection of contrast material, the wall and septa were discreetly enhanced (Fig-2). We noted the absence of $\mathrm{HC}$ intraparenchymal. An abdominal ultrasound was normal. A complete blood cell count showed showed a leukocytosis of 15450 cells/mm with a positif hydatid serology tests. 


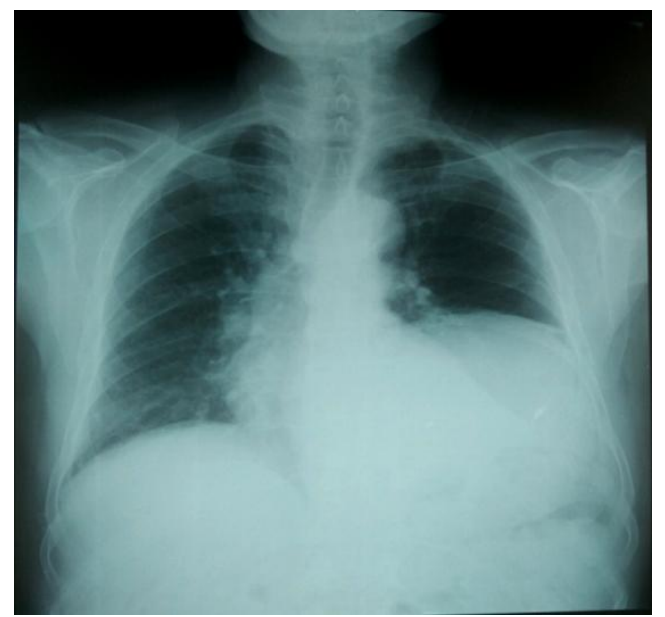

Fig-1: Chest X-ray showing rounded and homogeneous left basithoracic opacity
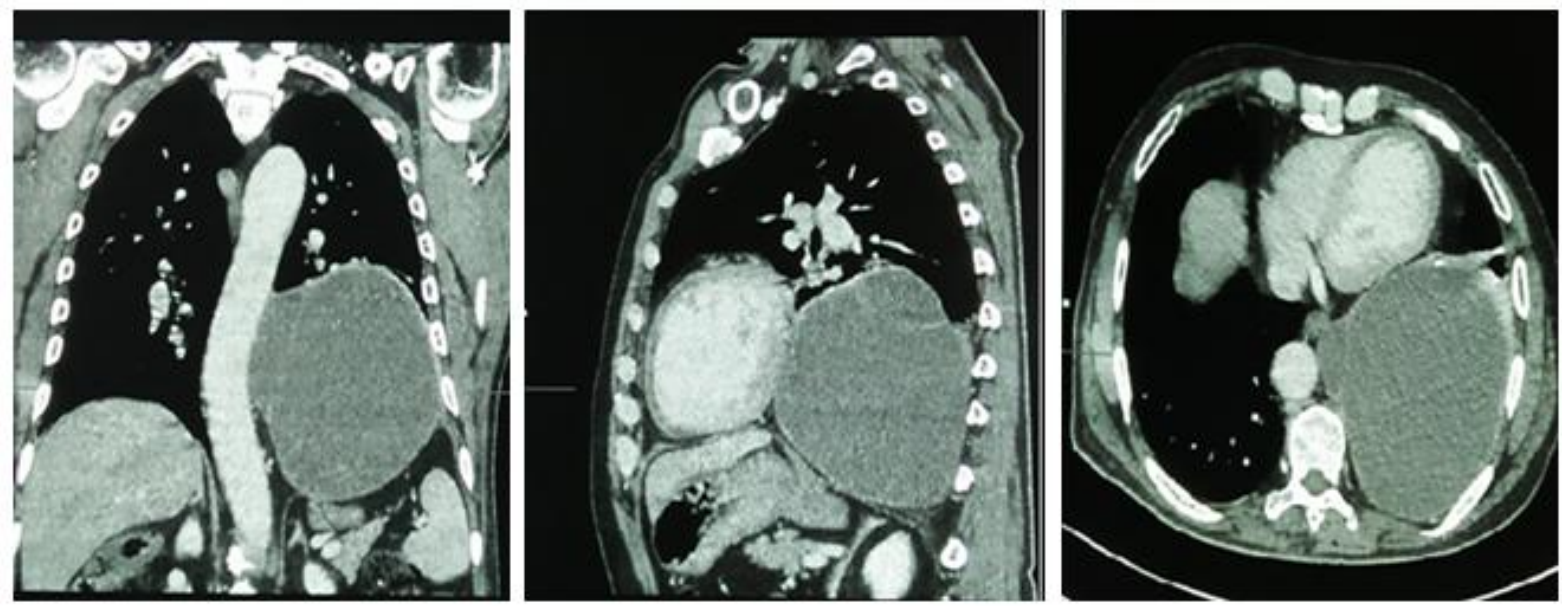

Fig-2: Chest computed tomography after injection of contrast, objectifying a liquid formation in the posterior mediastinum with regular contours and fine wall discreetly enhancing by the contrast, and showing the close relationship between the cyst and the aorta

\section{DISCUSSION}

Hydatid disease is a parasitic disease secondary to the development of the larval form of Echinococcus granulosus. Humans can be accidentally infested by ingesting food contaminated with parasite eggs or by direct contact with a sick dog. On entering the intestines of humans, the parasite gains further entry to locate itself in the liver or lung, and its passage into the systemic circulation is responsible for its location in diverse locations [5, 7]. These two organs are a blood filter for the dissemination of the parasite, thus explaining the rarity of hydatid in all other locations [5, 8]. Unlike the very frequent pulmonary parenchymal localizations in the endemic area, in particular in children $[9,10]$, the primary mediastinal localization of hydatid cyst is among the rarest. It represents $0.1 \%$ of all localizations and $1 \%$ of thoracic localizations [9, 1113].

The pathogenesis of mediastinal localization of $\mathrm{HC}$ remains controversial $[5,7,9]$. Some findings argue in favor of the hypothesis of fissuring an hydatid liver or lung into the systemic circulation, allowing the parasite to settle in the mediastinum $[1,5]$. Mediastinal localization could also come from transdiaphragmatic dissemination or via lymphatic abdominal hydatidosis [5].

Hydatic cyst of the mediastinum is often revealed by chest pain and signs of mediastinal compression, these symptoms vary according to the size of the lesions, the growth rate, and the location. In a study including 27 cases with mediastinal masses, $49 \%$ had chest pain, $37 \%$ had dyspnea, $11 \%$ had a cough, and $3 \%$ had superior vena cava syndrome [8, 14]. In addition to compression symptoms experienced by patients with mediastinal hydatid cysts, there may also be discovered by a complication as an embolism or anaphylaxis due to the rupture of the cyst in the bronchi or vessels; spread or infection of the ruptured cyst; cord compression due to intraspinal spread; and costal, vertebral, and chest wall erosions [1, 5, 6]. Imaging plays a vital role in the diagnosis and staging of lesions. Chest radiography oriented the diagnosis by showing a mediastinal water tone, often rounded or oval. Thoracic ultrasound allows confirmation of the diagnosis when the lesion is accessible. Thoracic ultrasound also reveals the fluid character of the opacity and, in many cases, the proligerous membrane, pathognomonic of $\mathrm{HC}[5,9]$, it also clarifies the univesicular or multivesicular structure 
characteristic of HC The thoracic. In the majority of cases, a chest CT can confirm the diagnosis by objectifying a mass of fluid density, often very limited, unmodified by the injection of contrast, however, contrast uptake by a pericyst can be observed [8, 9]. The cyst may also include thin walls testifying to its multivesicular character. The presence of peripheral calcifications supports diagnosis. A predilection for the posterior compartment of the mediastinum has been reported in the literature $[8,11]$.

Magnetic resonance imaging (MRI) is indicated in cases of intolerance to iodine or pregnant women. These different ways of cross-sectional imaging (ultrasound, CT, MRI) allow, in most cases, mediastinal hydatid cystic masses to be differentiated from other mediastinal cystic masses, such as enteric cyst, cystic lymphangioma, pleuropericardial cyst and bronchogenic cyst. Although these tests may lead to an accurate diagnosis, this is rather atypical for mediastinum located hydatid cysts, and the diagnosis is usually made postoperatively [8]. Hydatid serology is the only biologic aid to preoperative diagnosis. Its negativity does not exclude the diagnosis, but poses a diagnostic and therapeutic problem $[1,5]$. The hemagglutination, bentonite flocculation and latex agglutination tests are the procedures of choice at present. The fluorescent antibody test shows much promise, but requires further evaluation $[5,6]$.

Surgical treatment of mediastinal $\mathrm{HC}$ is essential. It consists of a cystectomy associated with total or partial pericystectomy. The surgical approach is according to cases, a posterolateral thoracotomy, anterolateral thoracotomy or median sternotomy $[1,9$, 11]. The postoperative course is classically simple with no mortality [1, 9]. No cases of recurrence have been described. The value of medical treatment based on albendazole remains controversial.

\section{CONCLUSION}

The mediastinum is an atypical location of hydatid cyst, rare even in endemic countries, must be considered in the differential diagnosis of cystic masses of the mediastinum, especially in endemic countries diagnosis is based on radiography, biology (hydatid serology) and histology study.

\section{REFERENCES}

1. Eroğlu, A., Kürkçüoğlu, C., Karaoğlanoğlu, N., Tekinbaş, C., Kaynar, H., \& Önbaş, Ö. (2002). Primary hydatid cysts of the mediastinum. European journal of cardio-thoracic surgery, 22(4), 599-601.
2. Petersen, C., \& Mills, J. (1994). Parasitic infections.Textbook of respiratory medicine, Philadelphia, PA: WB Saunders, 1201-1243.

3. Doğan, R., Yüksel, M., Cetin, G., Süzer, K., Alp, M., Kaya, S., ... \& Moldibi, B. (1989). Surgical treatment of hydatid cysts of the lung: report on 1055 patients. Thorax, 44(3), 192-199.

4. Karaoğlanoğlu, N., Gorguner, M., \& Eroglu, A. (2001). Hydatid disease of rib. The Annals of thoracic surgery, 71(1), 372-373.

5. Msougar, Y., Afandi, O., Ihfa, N., Baiz, Y., Rouiessi, Y., Khellouki, M., \& Finech, B. (2013). Mediastinal hydatid cyst: a case report. Journal of medical case reports, 7(1), 236.

6. Isitmangil, T., Toker, A., Sebit, S., Erdik, O., Tunc, H., \& Gorur, R. (2003). A novel terminology and dissemination theory for a subgroup of intrathoracic extrapulmonary hydatid cysts. Medical hypotheses, 61(1), 68-71.

7. Gasmi, M., Fitouri, F., Sahli, S., Sghairoun, N., \& Hamzaoui, M. (2010). Hydatidose médiastinale primitive chez l'enfant: à propos de deux cas. Revue de Pneumologie clinique, 66(6), 351354.

8. Kutluk, A. C., Kocatürk, C. İ., Ceyhan, S., Cansever, L., \& Bedirhan, M. A. (2017). A Posterior Mediastinal Hydatid Cyst. Respiratory Case Reports, 6(1):60-63.

9. Zidi, A., Zannad-Hantous, S., Mestiri, I., Ghrairi, H., Baccouche, I., Djilani, H., \& Mrad, K. B. M. (2006). Kyste hydatique primitif du médiastin: 14 cas. Journal de radiologie, 87(12), 1869-1874.

10. Hafsa, C., Belguith, M., Golli, M., Rachdi, H., Kriaa, S., Elamri, A., ... \& Gannouni, A. (2005). Imagerie du kyste hydatique du poumon chez l'enfant. Journal de Radiologie, 86(4), 405-410.

11. Beji, M., Messaoud, M. B., Louzir, B., Bouzaïdi, K., Rhouma, N. H. B., Cherif, J., ... \& Daghfous, J. (2004). Localisation cervico-thoracique d'un kyste hydatique. Journal de Radiologie, 85(2), 135-137.

12. Skalli, A. E. A., El Amraoui, F., Chikhaoui, N., \& Kadiri, R. (2000). Kyste hydatique du médiastin. À propos de 2 cas. Journal Radiol. 81:154-157.

13. Oğuzkaya, F., Akçali, Y., Kahraman, C., Emiroğullari, N., Bilgin, M., \& Şahin, A. (1997). Unusually located hydatid cysts: intrathoracic but extrapulmonary. The Annals of thoracic surgery, 64(2), 334-337.

14. Ayan, E., Balc1, A. E., Özalp, K., Duran, M., Vuraloğlu, S., \& Çekirdekçi, A. (2005). Mediastinal kitleler: 27 olgunun değerlendirilmesi. Türk Gögüs Kalp Damar Cer Derg, 13, 127-30. 